\title{
Self-Esteem, in Students of Yucatan, Mexico
}

\author{
Yolanda Oliva Peña, María Guadalupe Andueza Pech, Elsa María Rodríguez Angulo \\ Autonomous University of Yucatan, Mérida, Mexico \\ Email:opena@correo.uady.mx
}

How to cite this paper: Peña, Y. O., Pech, M. G. A., \& Angulo, E. M. R. (2019). SelfEsteem, in Students of Yucatan, Mexico. Psychology, 10, 411-423.

https://doi.org/10.4236/psych.2019.104028

Received: January 26, 2019

Accepted: March 3, 2019

Published: March 6, 2019

Copyright (c) 2019 by author(s) and Scientific Research Publishing Inc. This work is licensed under the Creative Commons Attribution International License (CC BY 4.0).

http://creativecommons.org/licenses/by/4.0/

\begin{abstract}
This study analyzes the relationship between self-esteem, in secondary school students, mainly of rural origin, with the ethnic condition, taken into consideration for this purpose the use of the language, in which we compare the Mayan speakers and non-Mayan speakers of a region of Yucatan, Mexico, in men and women. Quantitative, cross-sectional study, with a simple random sample of 1452 Yucatan high school students, by means of a selfadministered questionnaire. The main results are that $22 \%$ of the population has a low self-esteem level, with significant differences by age $(p=0.028)$ and in negative self-esteem score in the variable Maya-speaker and not Mayaspeaker $(p=0.023)$. There were also differences between the condition of rural and urban. The prevention and care of mental health in adolescence must take into account the peculiarities of cultural contexts and gender determinants, to strengthen the autonomy and self-esteem of new generations, educational programs based on studies that take into account the determinants social gender and ethnicity, now blurred before the global communication processes.
\end{abstract}

\section{Keywords}

Self-Esteem, Adolescents, Yucatan, Mexico

\section{Introduction}

Adolescence covers a period between 10 and 19 years, a period in which, among other things, physiological and psychological changes are experienced, and are in search of personal, family and social definitions. One of the most relevant factors in their socio-psycho-emotional development is particularly the integration of self-esteem, where the adolescent is forging his own being, through his thoughts, feelings, sensations and experiences that internalize about themselves.

The mental health of adolescents is crucial for their personal and family 
development, as well as for their integration in society and in terms of prevention, a crucial stage of adjustments that can be positively strengthened with support in various areas and to reach adequate levels of self-esteem, for the prevention of homicides, violence in general and in particular suicide. Suicides in this stage are increasingly frequent, it is estimated that around 800,000 people commit suicide per year, estimated in 2016 by the World Health Organization (WHO).

Suicide is considered a public health problem in Mexico with an estimated suicide rate per 100,000 inhabitants, which increased from 3.6 in 2000 to 5.1 in 2016 (INEGI). Chihuahua and Yucatán double the national rate with 11.4 and 10.2 suicides per 100000 inhabitants, respectively. Eight out of 10 suicides occurred during 2016 were committed by a man: this is 5116 of the 6291 suicides. In Yucatan, the figure rose to 191, of which 152 were men and 39 women, in the age range of 15 to 19 years, the INEGI reported 795 suicides throughout the country and 9 in Yucatan for the year 2017.

The WHO reminds us that preventing suicide is not an easy task, since mental health in general is considered socially in a negative and stigmatized manner, and few countries have committed to preventive programs and have focused on the population young (WHO, 2018).

Yucatán is one of the regions that concentrates a relevant ethnic population, which is visible through uses and customs and the permanence of the use of the Mayan language; at present, $25.63 \%$ of the communities communicate mainly with this language, which means the persistence of ethnic identity in at least 537,516 people aged 5 years and over registered in 2010 according to figures from the last population census of INEGI (2018).

There are few studies that refer to the relationship between the ethnic condition, basically defined from the everyday use of a language other than the official one and the relationship with self-esteem in adolescence, as a factor of protection, or as an important challenge, indispensable elements to be considered in suicide prevention programs and, in general, for a better level of mental health, since it is possible to assume that the social pressures and global processes offered by the "modern" culture to which they have access young people indisputably in the urban and rural areas, are elements that participate in the loss of identity as pointed out by Giddens (2000) and Bauman (2008, 2011), in a consumer society without content, dominated by extremisms, fundamentalisms, while at the same time, a kind of social inertia persists in the face of what exists, supported and normalized, of expectations and patterns of behavior. Global strategies of power are valuable in this modernity that Bauman calls "liquid societies", in which the social evolution of global and cultural humanity becomes insecure, of uncertainties, which can have negative effects on the mental health of young people, hence the importance of this work, when comparing Mayan and non-Mayan populations to determine the level of selfesteem in high school students and the effect. 
On the issue of ethnic populations and self-esteem, they have been scarcely documented, there are studies such as the one by Román \& Moreno, 2010; Esteban et al. (2011) that report on the personal identity of young people with ethnic affiliation, in which they find that it is associated with a life integrated to their communities of origin, giving rise to a positive self-esteem, so it is very important to know other contexts for evaluate this dynamic and, where appropriate, develop intervention programs that take into account the strengths and opportunities in each region.

According to Coopersmith (1968) we understand self-esteem as the evaluation that the individual makes about himself, expressed in an attitude of approval or disapproval and indicates how far he feels, capable, significant and ally, (cited in Montt \& Ulloa, 1996: p. 30).

The study of self-esteem must take into account that the formation of self-concept is integrated at different levels, one cognitive, one emotional-affective and another behavioral. In the same way, self-esteem can be understood from various perspectives, be it disciplinary or approaches (Silva Escorcia \& Mejía Pérez, 2015).

Also, self-esteem defines the affectivity of young people in their adolescent and adult life, structurally is composed of self-efficacy, which allows selfmotivation, self-concept and self-dignity that allow the realization of personality and self-realization which is one of the elementary foundations of emotional life (Silva Escorcia \& Mejía Pérez, 2015).

It is also worth mentioning that self-esteem is one of the most powerful indicators of psychological adjustment in young people; a positive self-esteem facilitates having a good psychological adjustment, and in turn, favors their social adaptation (Flores et al., 2010).

To study self-esteem Rosenberg and Coopersmith developed important instruments; Rosenberg focused his work on the study of global self-esteem and proposed to evaluate self-esteem in a holistic way by developing his Self-Esteem Scale in 1965, contrary to Coopersmith's instruments that value self-esteem in specific categories in different facets of his life.

The Rosenberg scale is widely used, it is considered one of the best measures to study global self-esteem and has been used for the development of subscales of self-esteem, instrument that is used for the present study (Atienza González et al., 2010).

In the stage of adolescence is when they recognize more difficulties in self-assessment, associated with the negative image they develop before the conceptions of others (Martínez Antón, 2007). According to studies by Montt \& Ulloa (1996), adolescents who have difficulties in self-image regarding their social performance are at risk of presenting some pathology of mental health, for young people in this stage of development. The authors point out that the academic performance does not represent greater relevance, evidenced in the fact of having repeated the school year had no impact on mental health.

Also, studies by Moreno Ruiz et al. (2009) suggested that adolescents who 
yearn for and seek an ideal social reputation have greater loneliness, lower self-esteem and feel more dissatisfied with their lives, on the contrary, adolescents who already have a social reputation has better self-esteem.

Martínez Antón et al. (2007) conducted a study to analyze the relationship between school variables (social adjustment valued by the teacher and social climate in the classroom) and indicators of psychosocial adjustment in adolescents (self-esteem, victimization and satisfaction with life). They used the Student Perception Scale by the teacher (EA-P), the School Climate Scale-CES, the Global Self-Esteem Questionnaire, the School Satisfaction Scale and the Life Satisfaction Scale to a sample of 1319 adolescents in public and private Spanish education centers. The main findings are that self-esteem has a positive effect on satisfaction with adolescent life and victimization a negative effect. There is also a significant and positive association between the social adjustment valued by the teacher and the social climate perceived by the adolescent.

On the other hand, (Montes González et al., 2012) observe that negative self-image is influenced by feeling unnecessary in their homes and by receiving little attention in it, at the same time not perceiving outselfs valued in school. On the other hand, high self-esteem is a reflection of the support received by their parents, who are proud of them. These same adolescents perceive themselves with little popularity, $31.3 \%$ consider themselves with low empathy and $42 \%$ believe that it should be different to have more friends. The study was carried out in Colombia to evaluate the self-esteem level of school-aged adolescents, through the validated scale of high self-esteem, in a sample of 259 rural school students. It was found that $47.9 \%$ of the students had low and very low self-esteem. And that at a younger age lower self-esteem, with a tendency to decrease after 14 years. Coinciding with studies by Gómez-Bustamante \& Cogollo (2010) who found a significant association between well-being and family functionality, concluding that the family is a very important element in the adolescent's social network.

Montt \& Ulloa (1996) conducted a study with the aim of identifying the relationship between social, family, school and personal self-esteem with mental health. They used the mental health questionnaire (it allows to discriminate with and without pathology) and the questionnaire of self-esteem of Coopersmith adapted, as well as the Survey of the family and socioeconomic level of 48 adolescents who attended a Mental Health Service. A significant relationship between general self-esteem and mental health was found. Just as high selfesteem was associated with normal mental health, but also a significant relationship between personal self-esteem (self-esteem) and social self-esteem.

Navarro Pardo et al. (2006) in the Spanish population conducted a study to explore the relationships of the five self-esteem factors with sociodemographic, family, personal and school variables, using the Clinical History and Selfconcept Questionnaire AF-5, in a sample of 148 patients attended by psychopathological problems in a mental health unit (infants and adolescents). Among its main findings are that personal and sociodemographic variables do not affect 
differentially any of the self-esteem factors. Also, there are differences depending on the age groups, the lowest self-esteem corresponds to the age group between twelve and sixteen years. Another aspect that was notorious is that having school problems on the part of adolescents only affects one area of self-esteem, the academic one, with which it is naturally related.

For their part, Flores et al. (2010) analyzed the relationships between the variables of self-esteem, self-efficacy and life satisfaction, and their association with gender and age. Using the Rosenberg Self-Esteem Scale, the Generalized Self-Efficacy Scale, the Scale for the Evaluation of Vital Satisfaction and the Scale for the Evaluation of the Parental Style in a sample of 2400 adolescents from Spanish rural and urban educational centers. The main results suggest that sex was significantly associated with the three variables studied, since boys scored higher than girls in these variables. Age did not significantly influence any of the variables studied. Regarding perception, it was recorded that the perception of better mood in the educational styles of parents was significantly related to self-esteem and life satisfaction.

In the case of Latin America, De Garrido Lecca (1997) conducted a study in Peru to find out the level of self-esteem that adolescents with poor school performance have, compared with those of average school performance. They used the Rorschtlch Psychodiagnosis, the self-centered indices according to therevised Wechsler Children's Intelligence Scale in 60 private and private school adolescents. It was observed that the subjects of the low performance group tend to present a higher proportion of reflex responses, these adolescents have been developing a greater effort to be able to cope and have difficulties for group participation. Thus, low-performing subjects presented a greater degree of self-concern.

Other problems that interfere with adolescents' self-esteem are insecurity and annoyance with their own body image (Sanchéz Crespo et al., 1997) adolescents with eating disorders have lower social self-esteem than adolescents without this condition, These adolescents focus their attractiveness on body image and emphasize the role of body image in the regulation of self-esteem (Gila et al., 2005).

This study analyzes the relationship between self-esteem, in secondary school students, mainly of rural origin, with the ethnic condition, taken into consideration for this purpose the use of the language, in which we compare the Mayan speakers and non-Mayan speakers of a region of Yucatan, Mexico, with a gender focus, to analyze the behavior of men and women, contrast that in the subject of self-esteem among students, has been scarcely documented so far in Mexico and particularly in Yucatan.

\section{Methodology}

Participants: A quantitative, cross-sectional study conducted on 1,432 high school students in the state of Yucatan, 50.6\% of the participants are men and $49.4 \%$ are women. With a minimum age of 12 years and a maximum of 18 years. $56.4 \%$ of the studied population is Spanish and $43.6 \%$ did not identify them- 
selves as Mayan speakers.

To measure self-esteem, the Rosemberg Scale was used, which consists of 10 items. The scale consists of 10 items, sentences of which five are enunciated positively and five negatively to control the effect of self-administered acquiescence. It has a reliability of 0.80 . The interpretation is made from items 1 to 5 , responses $\mathrm{A}$ to $\mathrm{D}$ are scored from 4 to 1 . From items 6 to 10, responses $\mathrm{A}$ to $\mathrm{D}$ are scored from 1 to 4 . From 30 to 40 points: Self-esteem high, normal; From 26 to 29 untos: average self-esteem, does not present serious problems, is to improve it. Less than 25 points: Low self-esteem. There are significant problems of self-esteem. Likewise, the analysis is made from the category of positive and negative self-concept, according to the type of expressions that the test considers. Likewise, two categories were created to analyze, positive self-esteem, taking into account the average in the answers of items 1 to 5 of the test, and negative self-esteem the average of the responses of items 6 to 10. Categories were created: high, medium and low for negative self-esttem. The data of the Mayanspeaking population was contrasted with non-Maya speakers.

Procedure: The study was carried out in localities of the interior of the state of Yucatan, corresponding to the East region, which is characterized as containing a strong proportion of the population of Mayan speakers, as well as localities of high marginalization. A random selection was made of schools, which include all types of secondary, community, telesecundarias, public secondary schools. The sample includes 22 schools, by simple random sampling. The information was collected in the 2017-2018 school year. Volunteer participation of all classrooms was invited. The statistical analysis was performed using descriptive statistics, and Student's $t$ test for mean difference and Chi square for ordinal variables, the results will be considered significant if $p<0.05$.

\section{Results}

Participants: a quantitative and cross-sectional study of 1432 high school students in the eastern part of the state of Yucatán. This study is relevant because it is one of the ones that presents one of the largest proportions of the population that conserves the uses and customs of the Mayan culture, which translates into the conservation of traditions and ways of interpreting and attending to education and work, as well as human interrelation, which are expressed in the oral communication through the Mayan language, as well as the practice of rites and uses of traditional dress, among other of the most evident and notorious features of cultural conservation.

Its location, the traditional way of subsistence rooted in the land with the cultivation of corn, the main product of the food of the Mexican and particularly of Yucatan, make the region an important space for cultural permanence, however, also the proximity to poles tourism, the introduction of school education in more and more population centers, and the environmental crisis, has pushed for the youth of the region to seek to emigrate in search of a future 
different from that marked by tradition. In this sample, the Maya-speaking and non-Maya speaking population of the region is contracted in order to observe an important aspect of emotional health that is the self-esteem of adolescents. The distribution of the sample was as follows: $56.4 \%$ were Maya speakers and $43.6 \%$ non-speakers.

The distribution by sex and age was as follows: $50.6 \%$ of the participants are men and $49.4 \%$ are women. $11.2 \%$ at the time of the study was 12 years old, $25.7 \%$ were 13 years old, $30.5 \%$ were 14 years old, 15 years old $21.6 \%, 16$ years old $7.5 \%, 17$ years old $3.1 \%$ and $0.4 \% 18$ years old.

As can be seen, the expected age range in this level of schooling is from 12 years to 15 years, however, there was an $11 \%$ with educational lag, when being between 16 and 18 years old, which leads us to think about the limitations that the contexts of High marginalization and the condition of Mayahablante can be factors of inequality in the opportunities of access and school success in these populations. The Rossemberg test is formulated considering positive and negative affirmations of the look towards oneself and the result of the balance in these parts is interpreted to define the level of self-esteem.

In the study, it shows that in the studied adolescents it observes in general terms a positive result, since $78.3 \%$ is located between the medium and high level of self-esteem. The population that registers a negative level of self-esteem, and that requires attention and support, in this study represents $21.7 \%$ of the adolescents, result although in terms of magnitude is reduced, in terms of protection to life and The prevention of mental health should be a cause for concern and attention of the school and health authorities that care for adolescents.

The cut-off point to determine low self-esteem is 25 , and it can be seen that the score range reached in this population was 7 points the minimum, registered by a woman; women registered a higher number of cases of low self-esteem than men (163 and 148 respectively), although in absolute terms it does not reflect significant differences if it is possible to notice that women registered the highest number of cases with the lowest scores ranging from 7 to 25 points, while ne men the scores go from 19 to 25 , which leads us to suppose that the severity in the low valuation of themselves is higher in women with respect to men.

The score of high self-esteem registered 40 points, this percentage was reached equally in men and women, with a total of 6 cases. In absolute terms, there were no significant differences in the elevated self-esteem score, but we can point out that with a difference of 6 cases, women recorded the highest number of cases that rejoice in high self-esteem. That is to say, the analysis by sex reflects that the self-esteem levels do not refer to significant differences in general terms, although there are differences in the distribution of the middle group and high self-esteem, and very low, since while in men there is a greater proportion in medium level, the percentage of self-esteem from medium to high is lower than that registered by men (45\%) women versus (41\%) (Table 1 ). 
Table 1. Distribution of the percentage according to level of self-esteem and sex.

\begin{tabular}{ccccc}
\hline Self-esteem level & Frequency/ & Percentage Man & Percentage Woman & $p$ Valor \\
\hline Low & $311(21.7)$ & $148(20 \%)$ & $163(23 \%)$ & \\
Half & $615(42.9)$ & $326(45 \%)$ & $289(41 \%)$ & \\
High & $506(35.3)$ & $250(35 \%)$ & $256(36 \%)$ & \\
Total & 1432 & 724 & 708 & $p=.60$ \\
\hline
\end{tabular}

Regarding the relationship between ethnicity (Mayans and non-speakers), it is observed that the average level of self-esteem predominates, followed by the high level, which together groups $78 \%$ of the students. In relative terms, the group of low self-esteem represents $22 \%$ for non-Mayan speakers and $21 \%$ in the group of Mayan speakers. It should be noted that the low level of self-esteem for the group of nomayabalantes indicates that women observe a lower number of men, while in the case of Maya speakers, women register a greater number of cases (6 cases versus 76 of the cases). Mayan-speaking men). In the case of the average level of self-esteem, it is $40.7 \%$ for the first case and $44 \%$ for the second. Which leads to notice that no significant differences are found between the groups. Finally, in the high level of self-esteem, $37 \%$ is recorded for non-students, for 35\% of Mayan speakers, which, as we observe practically in all levels of self-esteem, there are no significant differences between the levels of self-esteem observed among the students who refer to being or not being Maya speakers in the region.

However, when relating the type of locality, urban or rural, the result observes statistically significant differences $(p=0.002)$. At the rural level, the proportion of students with low self-esteem is higher and, in turn, the proportion of students with high self-esteem is lower. At the same time, more students are concentrated in the average self-esteem level (Table 2).

The analysis by sex of each level with respect to the urban and the rural reflects that, in the low level of self-esteem at urban level, only women register one more case than men; on the other hand, at rural level, there are significant differences between men and women (68 to 82 respectively), which leads to suppose a greater dissatisfaction among women who have low self-esteem (Table 3).

Likewise, significant differences were observed in the distribution of selfesteem levels according to age, which indicates that the younger the age, the greater the number of cases of low self-esteem, the lower age range stands at 15 years, comparing the level of self-esteem and comparing the average achieved in the 10 items $(p=0.020)$, both analyzes show significant differences according to age.

The breakdown by sex shows that women present a slight difference in the number of cases of low self-esteem with respect to men (110, 106 respectively) in the age range of 12 to 14 years and a greater difference in the range of 15 to 16 years (49 to 34 respectively), while in the age range of 17 to 18 years the number of cases is significantly lower ( 4 to 8 respectively), which leads to suppose that 
Table 2. Distribution of the level of self-esteem in Maya-speaking and sex.

\begin{tabular}{|c|c|c|c|c|c|}
\hline & Mayan speaker & & Man & Woman & Total \\
\hline \multirow{4}{*}{ Not } & & Low & 72 & 67 & 139 \\
\hline & level of self-esteem & Half & 127 & 131 & 258 \\
\hline & & High & 124 & 103 & 227 \\
\hline & Total & & 323 & 301 & 624 \\
\hline \multirow{4}{*}{ Yes } & & Low & 76 & 96 & 172 \\
\hline & level of self-esteem & Half & 199 & 158 & 357 \\
\hline & & High & 126 & 153 & 279 \\
\hline & Total & & 401 & 407 & 808 \\
\hline \multirow{4}{*}{ Total } & & Low & 148 & 163 & 311 \\
\hline & level of self-esteem & Half & 326 & 289 & 615 \\
\hline & & High & 250 & 256 & 506 \\
\hline & Total & & 724 & 708 & 1432 \\
\hline
\end{tabular}

Table 3. Distribution of the level of self-esteem in urban or rural location and sex.

\begin{tabular}{|c|c|c|c|c|c|}
\hline & \multirow{2}{*}{ Urb_rural } & & \multicolumn{2}{|c|}{ Sex } & \multirow{2}{*}{ Total } \\
\hline & & & Man & Woman & \\
\hline \multirow{4}{*}{ Urbano } & & Low & 80 & 81 & 161 \\
\hline & level of self-esteem & Half & 159 & 165 & 324 \\
\hline & & High & 161 & 149 & 310 \\
\hline & Total & & 400 & 395 & 795 \\
\hline \multirow{4}{*}{ Rural } & & Low & 68 & 82 & 150 \\
\hline & level of self-esteem & Half & 167 & 124 & 291 \\
\hline & & High & 89 & 107 & 196 \\
\hline & Total & & 324 & 313 & 637 \\
\hline \multirow{4}{*}{ Total } & & Low & 148 & 163 & 311 \\
\hline & level of self-esteem & Half & 326 & 289 & 615 \\
\hline & & High & 250 & 256 & 506 \\
\hline & Total & & 724 & 708 & 1432 \\
\hline
\end{tabular}

the older the women become stronger (Table 4).

The Rosemberg scale we have applied in this study shows the negative self-concepts separately, when analyzing them we find that the average level predominates in the negative score, with men predominating at this level, while at the most high on the negative concept of themselves, it is women who register the greatest number of cases, at the same time as at the lowest level as well. that is, the ends, as shown in Table 5.

Also, it is observed that age also has a significant relationship in terms of 
Table 4. Distribution of the level of self-esteem by age groups and sex.

\begin{tabular}{|c|c|c|c|c|c|}
\hline & \multirow{2}{*}{ Age groups } & & \multicolumn{2}{|c|}{ Sex } & \multirow{2}{*}{ Tota } \\
\hline & & & Man & Woman & \\
\hline \multirow{4}{*}{$12-14$} & & Low & 106 & 110 & 216 \\
\hline & level of self-esteem & Half & 206 & 213 & 419 \\
\hline & & High & 161 & 169 & 330 \\
\hline & Total & & 473 & 492 & 965 \\
\hline \multirow{4}{*}{$15-16$} & & Low & 34 & 49 & 83 \\
\hline & level of self-esteem & Half & 102 & 65 & 167 \\
\hline & & High & 85 & 82 & 167 \\
\hline & Total & & 221 & 196 & 417 \\
\hline \multirow{4}{*}{$17-18$} & & Low & 8 & 4 & 12 \\
\hline & Autoestima agrupada & Half & 18 & 11 & 29 \\
\hline & & High & 4 & 5 & 9 \\
\hline & Total & & 30 & 20 & 50 \\
\hline
\end{tabular}

Table 5. Negative self-concept by sex.

\begin{tabular}{ccc}
\hline & Man & Woman \\
\hline High & 161 & 180 \\
Half & 472 & 420 \\
Low & 91 & 108 \\
Total & 724 & 708 \\
\hline
\end{tabular}

negative self-concept. Table 6 shows that the participation of the age group of 12 to 14 years is greater, mainly, at higher age lower score on negative self-esteem, therefore better self-concept, differences that turn out to be significant with ( $p<$ $0.001)$. It is also possible to mention that in the range of 12 to 14 years, that women have a higher number of cases for high level as well as low levels, so this age range refers to greater vulnerability for sex.

\section{Discussion}

The significant relationship between the general self-esteem and the mental health of adolescents has been documented (Navarro Pardo et al., 2006), hence the importance of knowing the situation of young people in a global world that affects all areas of social life and personal, through a continuous flow of messages and experiences, offers, aesthetic models, forms of health care, of human relationship, which have been adopted differently by sex, to model gender behavior and are assimilated by young people, in each context and for each culture in a particular way.

Our study with respect to the distribution of self-esteem levels differed from 
Table 6. Negative self-concept by age and sex.

(a)

\begin{tabular}{cccc}
\hline Men & $\mathbf{1 2}$ to 14 & $15-\mathbf{1 6}$ & $17-\mathbf{1 8}$ \\
\hline High & 113 & 40 & 8 \\
Half & 301 & 151 & 20 \\
Low & 59 & 30 & 2 \\
Woman & 12 to 14 & $15-16$ & $17-18$ \\
High & 127 & 48 & 5 \\
Half & 288 & 118 & 14 \\
Low & 77 & 30 & 1 \\
\hline
\end{tabular}

(b)

\begin{tabular}{cccc}
\hline Negative self-concept & 12 a 14 & $15-16$ & $17-18$ \\
\hline High & 8 & 0 & 0 \\
Half & 749 & 267 & 45 \\
Low & 208 & 150 & 5 \\
\hline
\end{tabular}

that found by Montes González et al., 2012, since we only found 21.7\% in low self-esteem, while in a similar population, of rural origin, the authors found $47.9 \%$.

Regarding behavior by sex, we found that the percentages of men and women do not differ significantly in terms of positive self-esteem levels, but in the distribution of each level of self-esteem, results that agree with Flowers et al. (2010) and also in terms of age, the negative self-concept differs, as Navarro Pardo et al. (2006), in which at a younger age the level of negative self-concept increases.

The studies that have related the condition of gender and ethnicity and its relation with the self-esteem are reduced; Our results indicate that, in general terms, young Mayan speakers register proportionally better levels of self-esteem, in comparison with those registered in non-Mayan people, findings that coincide with that reported by Román and Moreno, 2010; Esteban et al. (2011), who refer that ethnic identity strengthens students' self-esteem.

\section{Conclusion}

The prevention and attention to mental health of young people requires strategies based on the understanding of social determinants and the improvement of local capacities that are protective elements of health, as is the case of the cultures and community contexts that favor it.

Rural contexts and high marginalization contribute to the generation of vulnerabilities that create gaps in access to opportunities for integral human development, so mental health is a core aspect to provide new generations with tools for life, which initiate with a high self-esteem. 
Our findings suggest that the condition of rurality, as well as age and in certain aspects, being a woman are elements that must be taken into account in order to strengthen and work in schools programs focused on reducing social gaps in students.

Especially we find that students from 12 to 14 years old express the greatest disadvantages in self-esteem, which leads us to link the biological changes, the change from the basic school cycle to the secondary school, as a whole they can be pushing the younger students to a lower worth of themselves, which requires addressing in the teaching programs in schools and with parents to support their development, and address it as a social phenomenon, and as a human rights issue.

\section{Conflicts of Interest}

The authors declare no conflicts of interest regarding the publication of this paper.

\section{References}

Atienza González, F., Moreno Sigüenza, Y., \& Balaguer Solá, I. (2010). Análisis de la dimensionalidad de la Escala de Autoestima de Rosenberg en una muestra de adolescentes valencianos. Revista de Psicología, 1-2.

Bauman, Z. (2008). La cultura en el mundo de la modernidad líquida. México: FCE.

Bauman, Z. (2011). Daños colaterales. Desigualdades sociales en la era global. México: FCE.

De Garrido Lecca, M. (1997). Autoestima en adolescentes con bajo rendimiento escolar a través del psicodiagnóstico de Rorschach. Revista de Psicología, 15, 179-199.

Esteban, M., Rivas, M., \& Pérez, M. (2011). Identidad étnica y autoestima en jóvenes indígenas y mestizos de San Cristóbal de las Casas (Chiapas, México). Acta Colombiana de Psicología, 14, 99-108. http://www.scielo.org.co/pdf/acp/v14n1/v14n1a09.pdf

Flores, M., Oliva Delgado, A., \& Parra Jiménez, A. (2010). Percepciones de autoevaluación: Autoestima, autoeficacia y satisfacción vital en la adolescencia. Psychology, Society \& Education, 2, 55-69.

Giddens, A. (2000). Un mundo desbocado. Los efectos de la globalización en nuestras vidas Madrid, Taurus.

Gila, A., Castro, J., Gómez, M., \& Toro, J. (2005). Social and Body Self-Esteem in Adolescents with Eating Disorders. International Journal of Psychology and Psychological Therapy, 5, 63-71.

Gómez-Bustamante, E. M., \& Cogollo, Z. (2010). Factores predictores relacionados con el bienestar general en adolescentes estudiantes de Cartagena, Colombia. Revista de salud pública, 12, 61-70. https://doi.org/10.1590/S0124-00642010000100006

INEGI (2018). Comunicado de prensa núm. 410/18 7 de septiembre de 2018. http://www.beta.inegi.org.mx/contenidos/saladeprensa/aproposito/2018/suicidios2018 Nal.pdf

Martínez Antón, M., Buelga Vázquez, S., \& Cava, J. (2007). La satisfacción con la vida en la adolescencia y su relación con la autoestima y el ajuste escolar. Anuario de psicología/The UB Journal of Psychology, 38, 293-303.

Montes González, I. T., Escudero Ramírez, V., \& Martínez, J. W. (2012). Nivel de 
autoestima de adolescentes escolarizados en zona rural de Pereira, Colombia. Revista Colombiana de Psiquiatría, 41, 485-495.

https://doi.org/10.1016/S0034-7450(14)60024-X

Montt, M. E., \& Ulloa, C. F. (1996). Autoestima y salud mental en los adolescentes. Salud Mental, 19, 30-35.

Moreno Ruiz, D., López Estévez, E., Pérez Murgui, S., \& Musitu Ochoa, G. (2009). Reputación social y violencia relacional en adolescentes: el rol de la soledad, la autoestima y la satisfacción vital. Psicothema, 21, 537-542.

Navarro Pardo, E., Tomás Miguel, J. M., \& Oliver Germes, A. (2006). Factores personales, familiares y académicos en niños y adolescentes con baja autoestima. Boletín de psicología, 88, 7-25.

Román, \& Moreno (2010). Autoestima en jóvenes indígenas: borucas y térrabas self-esteem in young indigenous: Borucas and terrabas. Rev. Ciencias Sociales, 126-127, 33-44. https://revistas.ucr.ac.cr/index.php/sociales/article/view/8786/8272

Sanchéz Crespo, G., Jiénez Gómez, F., \& Barragán Merino, V. (1997). Autoestima y autoconcepto en adolescentes: Una reflexión para la orientación educativa. Revista de Psicología, 15, 201-221.

Silva Escorcia, I., \& Mejía Pérez, O. (2015). Autoestima, adolescencia y pedagogía. Revista electrónica educare, 19, 241-256.

WHO (2018). Suicide: Facts and Figures.

https://www.who.int/es/news-room/fact-sheets/detail/suicide 